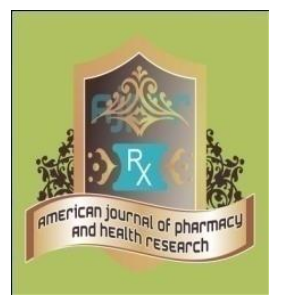

Review Article

AMERICAN JOURNAL OF PHARMACY AND HEALTH

RESEARCH

www.ajphr.com

2020, Volume 8, Issue 4

ISSN: 2321-3647(online)

\title{
Palladium used As A Catalyst: A Review
}

\author{
Bilal A Bhat*1 , Wasseem Akbar Khanday*2 \\ 1. Department of Chemistry, Govt Degree College, Shopian (192303), J \& K India. \\ 2.Department of Chemistry, Shri Venkateshwara University, Gajraula Utter Pradesh
}

\begin{abstract}
In this review, the most important $\mathrm{Pd}$-catalyzed $\mathrm{C}-\mathrm{C}$ cross-coupling named reactions have been presented and discussed. It has been proposed that in Pd-catalysed reactions, the Pd decreases the activation energy or reacting species by simply stabilizing the transition state as it is an unstable and short-lived. The catalyst may get coordinated to one or more of the reactants and remains coordinated throughout the transition state of the catalytic process. During this process, the dissociation of the product either regenerates the Pd directly or generates a species that will be converted into the Pd. This is a typical in enzyme-catalyzed processes occurs in organometallic chemistry.
\end{abstract}

Keywords: Cross-coupling, Catalytic, enzyme, organometallic, short-lived. 


\section{INTRODUCTION}

Palladium is used as homogeneous catalyst in many coupling reactions. In this direction, a number of palladium-catalysed cross coupling reactions were carried out by different scientists. Heck (1968) reported an in situ-generated methyl- and phenyl palladium halides ( $\mathrm{RPdX} ; \mathrm{R}=\mathrm{Me}, \mathrm{Ph}$; $\mathrm{X}=$ halide) when added to olefins at room temperature leads to formation of styrene. This reaction became one of the most important reactions for making carbon -carbon single bonds ${ }^{\mathbf{1}}$ Suzuki et al (1979) reported a novel palladium catalyzed cross- coupling reaction between aryl boronic acids and aryl halides ${ }^{\mathbf{2 - 3}}$ which have a diverse spectrum of applications, ranging from pharmaceuticals to material sciences. In addition, Negishi showed one example of coupling with an alkynyl boron compound. Also, N. Miyaura, made lot of improvements on boron couplings. The Suzuki reaction has been extended to aryl chlorides by G. C. Fu by the use of sterically hindred phosphine ligands ${ }^{4}$.The Sonogashira coupling reaction has been employed in a wide variety of reactions, because of formation of carbon-carbon bonds carried out at room temperature in aqueous media and mild base, which helps in the synthesis of wide variety of complex molecules .It finds wide spectrum of applications in pharmaceuticals, natural products, nanomaterials and organic materials. In this review, a collection of Pd-catalysed named reactions has been presented and discussed.

\section{Heck Reaction}

The Heck reaction is also referred to as the Mizoroki-Heck reaction as discovered by Tsutomu Mizoroki and Heck in 1972 through independent research. It is a Pd catalyzed cross-coupling reaction between alkenes and aryl or vinyl halides to form a substituted alkenes (Fig. 1). This is

the first reaction to present $\mathrm{C}-\mathrm{C}$ bond forming reaction. It is highly stereoselective in nature. ${ }^{\mathbf{5}}$. Heck proposed both inter and intramolecular reactions are known used for construction of rings of variable size with high degree of region and stereoselectivity. This mechanism is used in a wide range of applications for the preparation of hydrocarbons, novel polymers, dyes, pharmaceuticals and natural products ${ }^{6-10}$. 


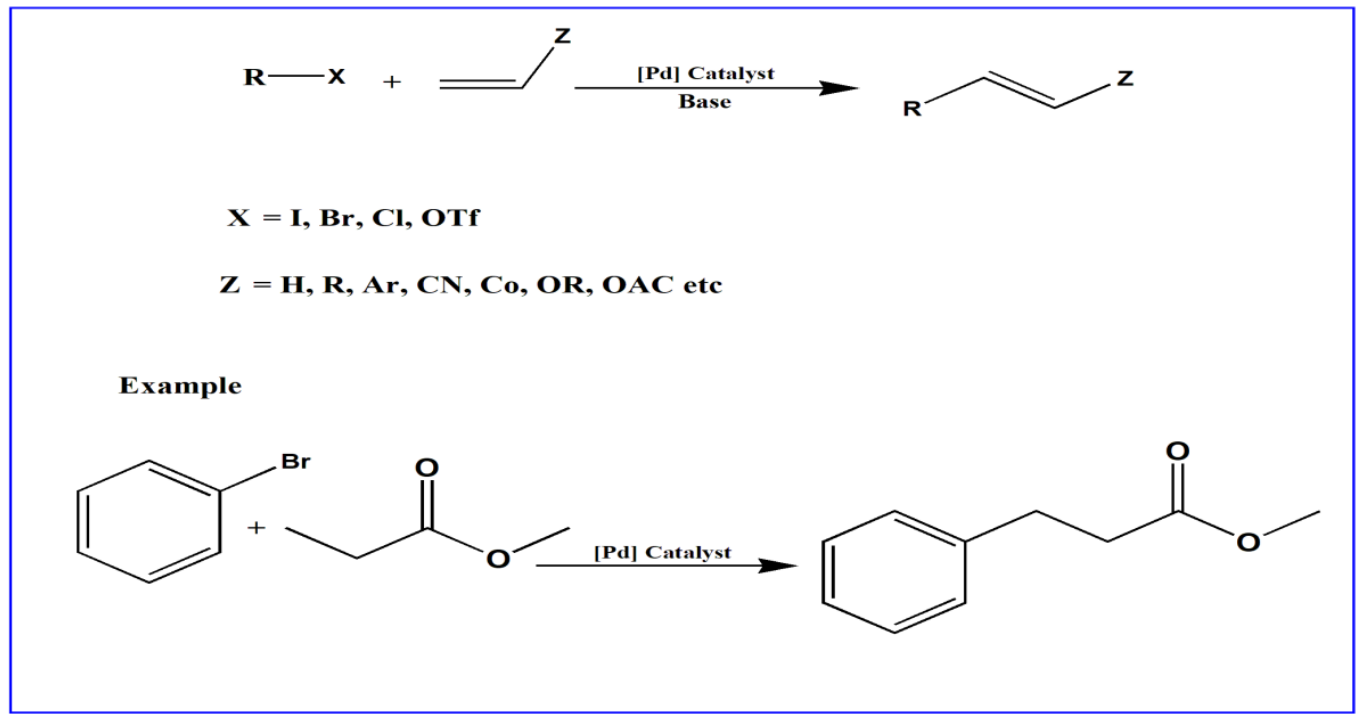

Figure 1: Intermolecular Heck reaction

The general mechanism of catalytic cycle begins with oxidative addition on $\mathrm{Pd}(0)$ complex to form Pd (II) complex is presented in (Figure 2).

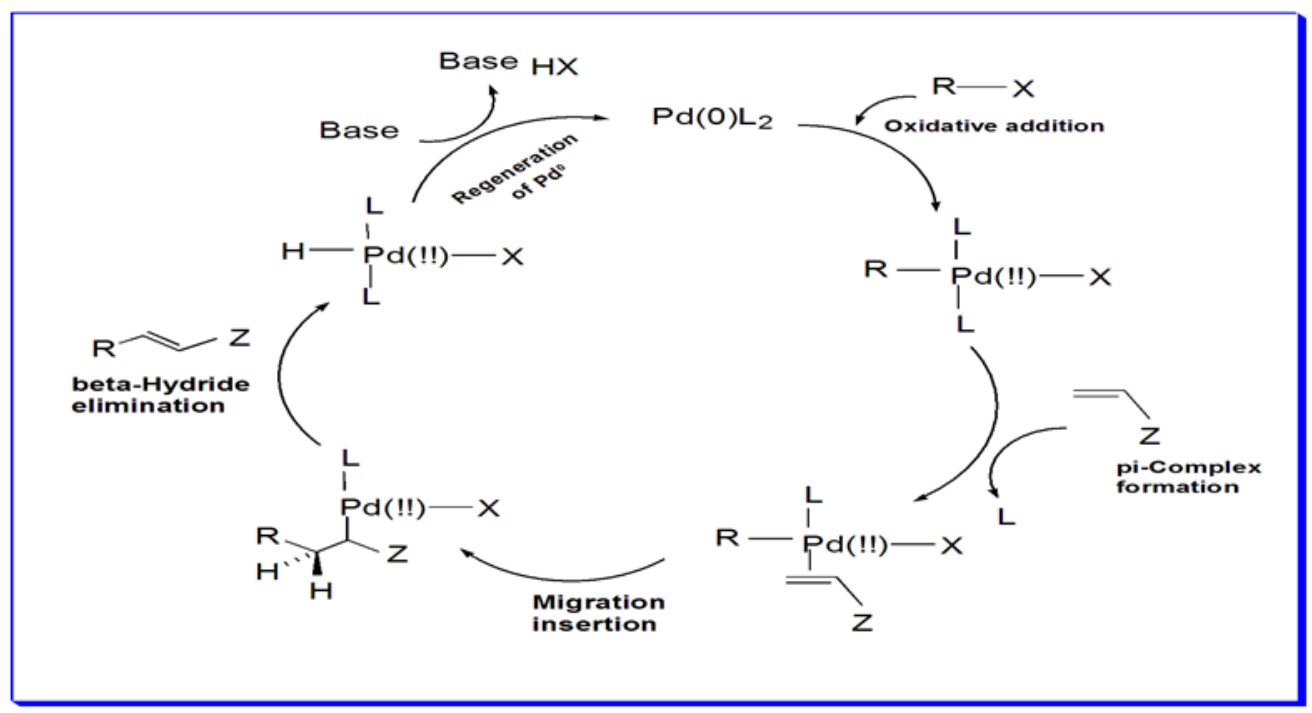

Figure 2: Mechanism for the Heck reaction

\section{Suzuki-Miyaura Reaction/Suzuki Cross-coupling}

The Suzuki-Miyaura cross-coupling reaction was first published in 1979 by Akira Suzuki and Norio Miyaura. It is also known as the Suzuki-Miyaura reaction or Suzuki coupling. It is a palladium catalyzed cross-coupling reaction between an organic born compounds $\left(\mathrm{R}^{2}-\mathrm{B}-(\mathrm{OR})_{2}\right)$ and organic halides $\left(\mathrm{R}^{1}-\mathrm{X}\right)$ in the presence of a base for the activation of the boron compound and proceeds under mild conditions finds wide application for the synthesis of pharmaceuticals and total synthesis of complex natural products ${ }^{\mathbf{1 1}-16}$ (Figure 3). The Suzuki -Miyaura reaction mechanism occurs in 3 general steps. 
1. Oxidative addition

2. Transmetalation

3. Reductive elimination.

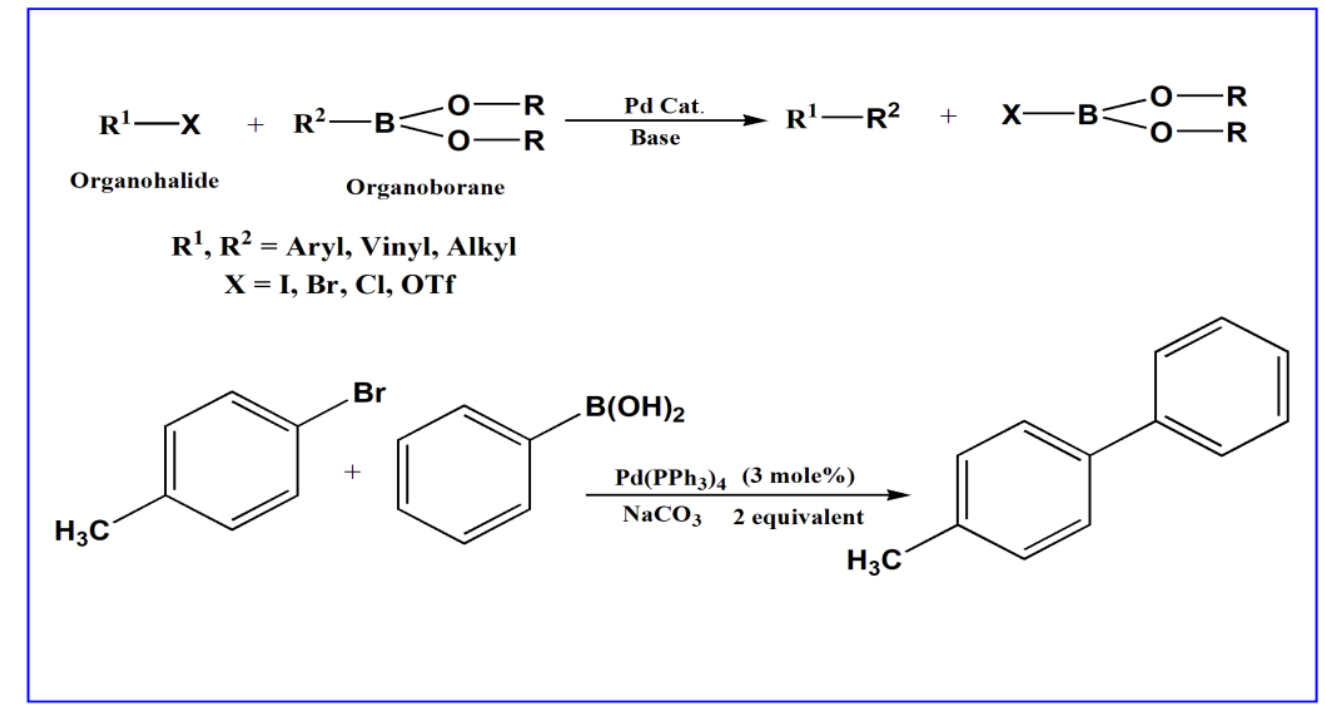

Figure 3: Suzuki- Miyaura Reaction/Suzuki Cross-coupling reaction

In the mechanism, two reaction pathways have been proposed (Figure 3). In the Pathway A the coordination of base to the organoboron compound undergo organoboronate formation, which undergoes nucleophilic attack on a palladium halide complex. On the other hand, pathway B base undergo halide substitution in the coordination sphere of the catalyst and the subsequent reaction with a neutral organoboron compound ${ }^{17}$. It was proposed that the pathway A involving the organoboronate species is the most favourable.

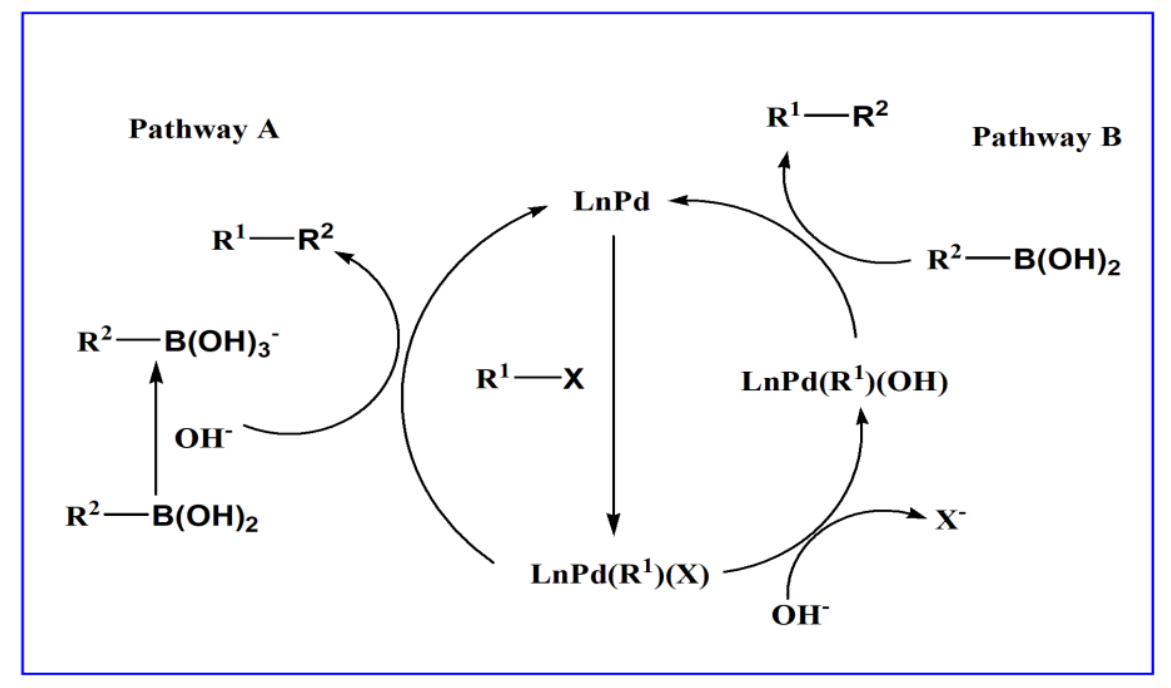

Figure 4 Suzuki-Miyaura cross-coupling reaction.

The overall mechanism of Suzuki cross-coupling reaction begins with oxidative addition of the organ halide to the $\mathrm{Pd}(0)$ to form a $\mathrm{Pd}$ (II) complex. A molecule of the hydroxide or alkoxide base 
then replaces the halide on the palladium complex, while another adds to the organoborane to form a borate reagent making its $\mathrm{R}$ group more nucleophilic. Transmetalation with the borate then follows by which $\mathrm{R}$ group replaces the halide anion on the palladium complex. Reductive elimination then leads final product formation with the regeneration of palladium catalyst (Figure $4)^{18}$.

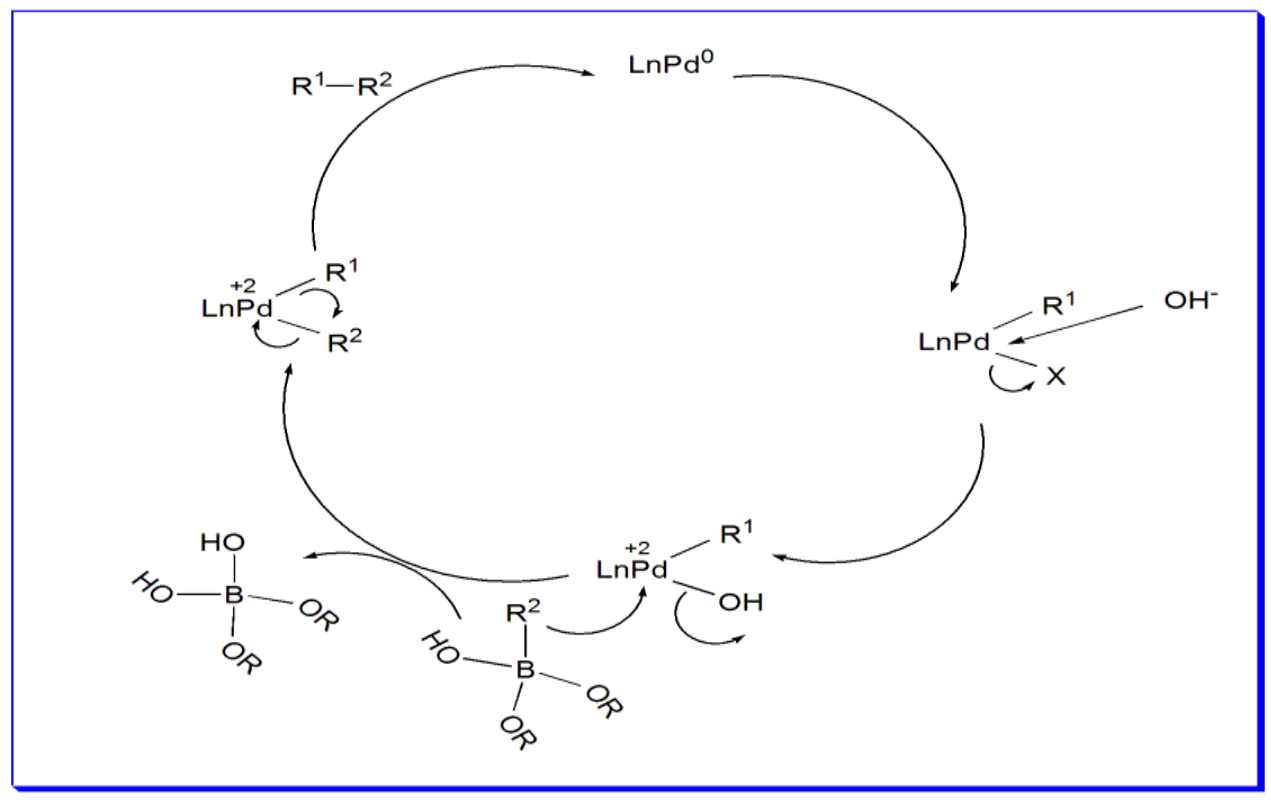

Figure 4 mechanism of Suzuki cross- coupling reaction

The rate determining step of the catalytic cycle is oxidative addition. (Fig 5)

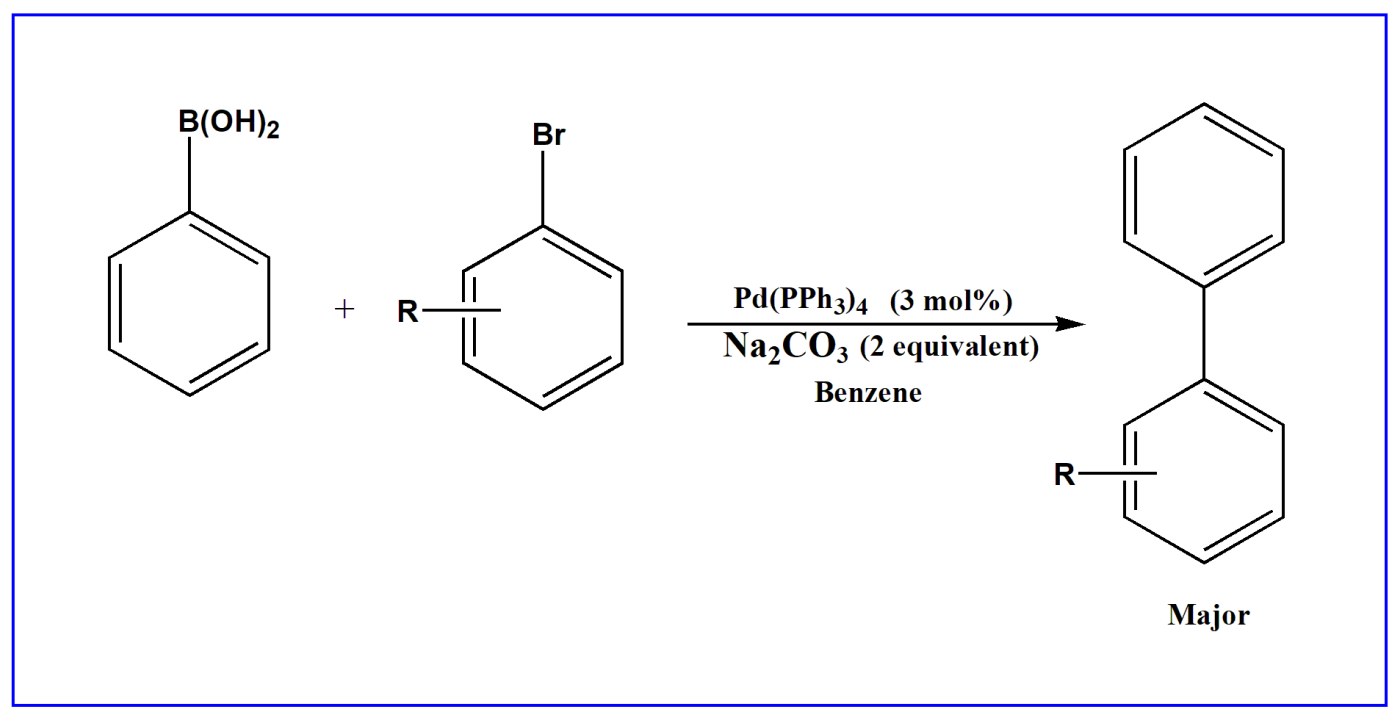

Figure 5 Stereochemistry of oxidative addition reaction

\section{Negishi Cross-Coupling reaction}

This reaction is named after Ei-ichi Negishi which is widely employed for transition metal catalyzed cross-coupling reaction. It involves the coupling between an organic halide $\left(\mathrm{R}^{1}-\mathrm{X}^{1}\right)$ and 
an organozinc Compund like aryl- and benzyl zinc derivatives with aryl halides in the presence of a catalytic amount of a $\mathrm{Ni}$ or $\mathrm{Pd}^{\mathbf{1 9}}$ (Fig. 6). Among the most $\mathrm{C}-\mathrm{C}$ cross-coupling reactions, the Negishi reaction is commonly catalyzed by Ni or Pd complexes. ${ }^{20}$.

$$
\begin{aligned}
& \begin{array}{lll}
\mathrm{R}^{1}-\mathrm{X}^{1}+\mathrm{R}^{2}-\mathrm{Zn}-\mathrm{X}^{2} \stackrel{\text { Cat. } \mathrm{Pd}(\mathrm{o}) / \text { Ligands }}{ } \underset{\mathrm{R}^{1}-\mathrm{R}^{2}}{ } & \text { Or Cat. Ni/Ligands } & \text { Coupling product } \\
\mathrm{R}^{1}=\text { aryl, alkenyl, alkynyl...... } & &
\end{array} \\
& \mathrm{X}^{1}=\mathrm{Cl}, \mathrm{Br} \text {, I, OTf, OAC } \\
& \mathrm{R}^{2}=\text { aryl, alkenyl, benzyl } \\
& \mathrm{X}^{2}=\mathrm{Cl}, \mathrm{Br}, \mathrm{I}
\end{aligned}
$$

\section{Figure 6 Negishi cross-coupling reaction}

The Negishi coupling reaction must be performed in an oxygen and water free environment because the organozinc compounds are moisture and air sensitive. This has become a fact that has hindered its use relative to other cross- coupling reactions.

The reaction mechanism of Negishi cross-coupling reaction is thought to proceed via a standard Pd catalyzed cross-coupling $\operatorname{Pd}(0)$ species, which is oxidized to $\mathrm{Pd}(\mathrm{II})$ in an oxidative addition step involving the organohalide species ${ }^{\mathbf{2 1}}$. This step proceeds with aryl, vinyl, alkynyl and acyl halides triflates or acetates, with substrates following standard oxidative addition relative rates( I > Otf > $\mathrm{Br}>\mathrm{Cl}$ ) (Fig. 7)

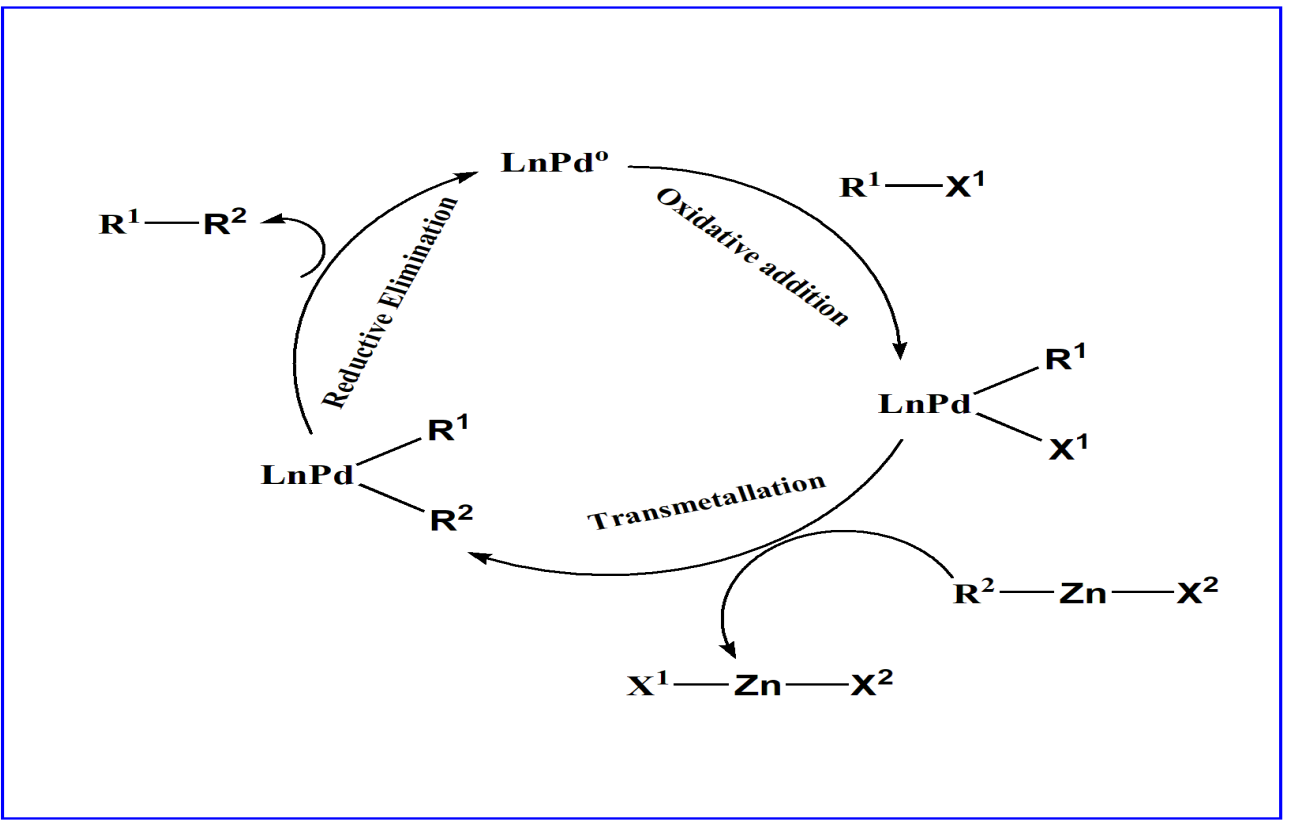

Figure 7 Mechanism for the Pd-catalyzed Negishi reaction 
The additions of cis- Pd (II) complex rapidly isomerizes to the trans-complex ${ }^{22}$ (Fig. 8)

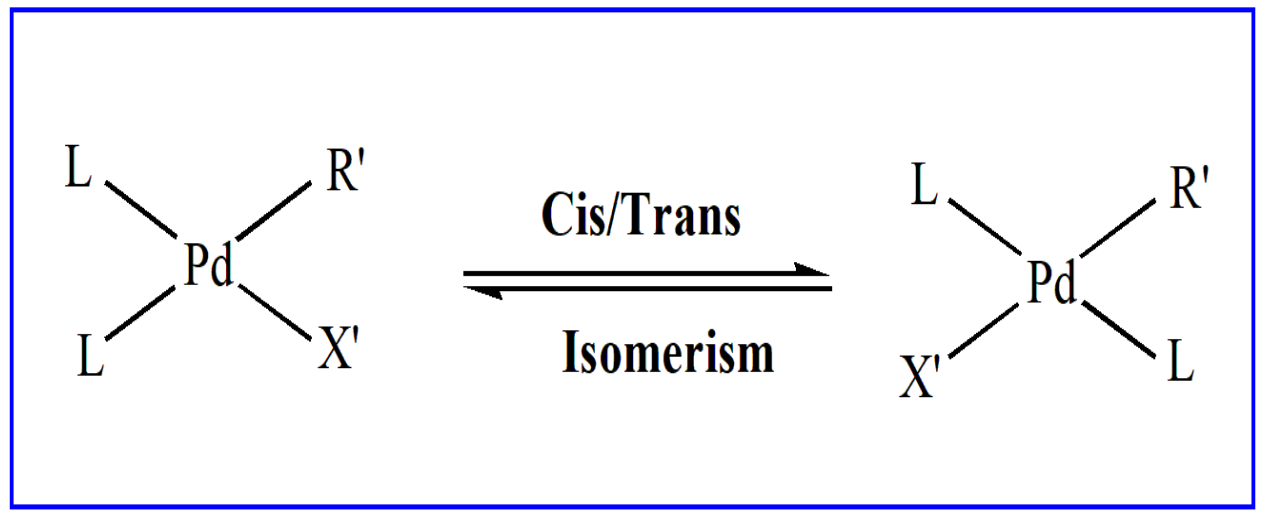

Figure 8 cis/trans isomerisation

This reaction is most importantly used in synthetic processes such as the synthesis of fine chemicals, pharmaceuticals or natural products ${ }^{23-25}$. Furthermore, the peculiarity of this reaction is that it can be carried out using two types of organometallic reagents, $\mathrm{ZnR}_{2}$ or $\mathrm{ZnRX}$ but among the two has been found experimentally that all the reactions with $\mathrm{ZnMe}_{2}$ are faster than with $\mathrm{ZnMeCl}$.

\section{Sonogashira Cross Coupling Reaction}

The Sonogashira reaction (also called the Sonogashira-Hagihare reaction) is a cross-coupling reaction used in organic synthesis to form carbon-carbon bonds. It is a cross coupling reaction between aryl or vinyl halides with terminal alkynes to generate conjugated enynes and arylalkynes (Fig. $9 \& 10$ ) in the presence of a Palladium (0) catalyst, a copper (I) cocatalyst, and an imine base $^{\mathbf{2 6}}$. This reaction is widely used for preparing arylacetylenes and conjugated enynes ${ }^{\mathbf{2 7}-\mathbf{3 0}}$ used as precursors for natural products, pharmaceuticals, and materials with specialized optical and electronic properties.

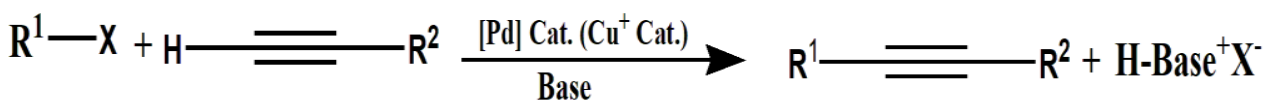

$$
\begin{aligned}
& \mathrm{R}^{1} \text { = alkyl, alkenyl, alkyl, } \mathrm{SiR}_{3} \text { etc } \\
& \mathrm{R}^{2}=\text { aryl, vinyl etc } \\
& \mathrm{X}=\mathrm{I}, \mathrm{Br}, \mathrm{Cl}, \mathrm{OTf}
\end{aligned}
$$




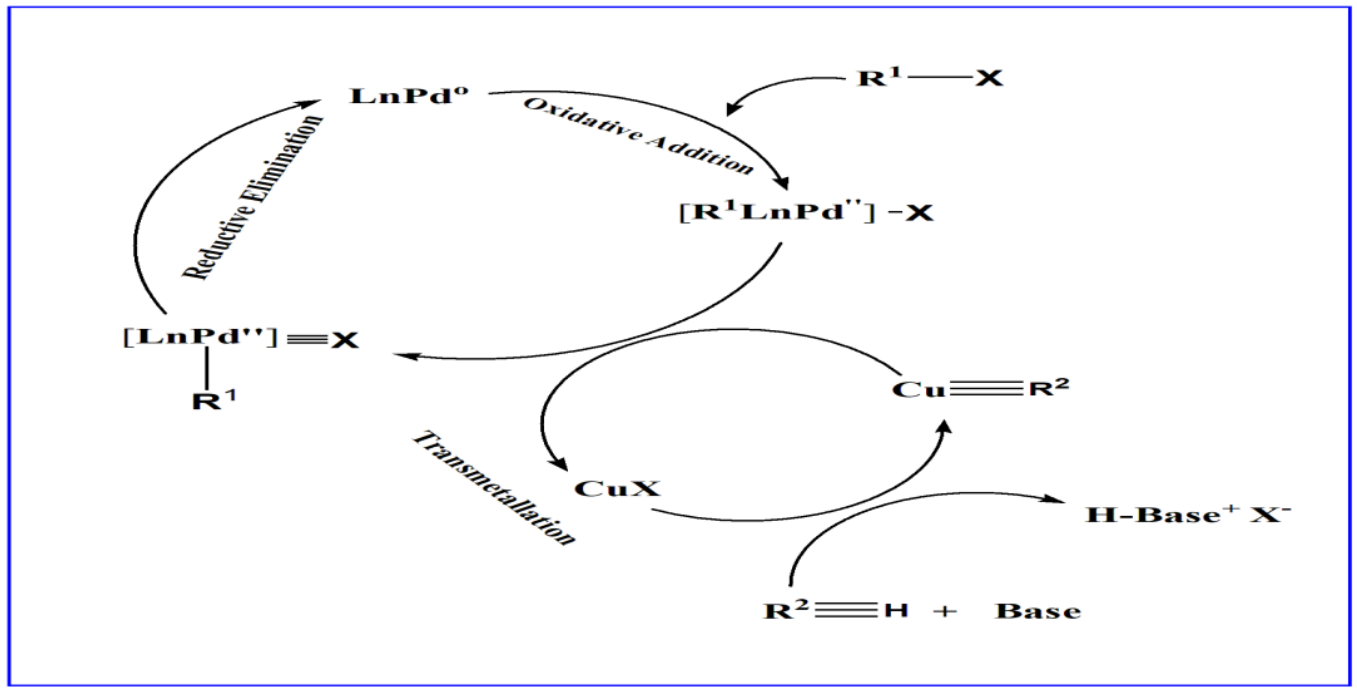

Figure $9 \& 10$ Pd-catalyzed Sonogashira reaction

Furthermore, copper (I) salt acts as co-catalyst in the Sonogahira reaction in order to facilitate the reaction by the in situ generation of copper acetylide. However, several modifications of the original Sonogashira reaction have been also recently reported which have been carried out under amine-free, ligand free and solvent free conditions ${ }^{31}$.

\section{CONCLUSION}

In the present review, the main attention was concentrated on to the study of pd-catalyzed reactions proposed by different chemists. The whole literature survey was carried out to understand the nature of the named C-C coupling reactions and was compiled for future research. This may help the researcher, scholars and even students to design Pd catalysed reactions with great efficiency. The main focus of future research will be developing and exploring new $\mathrm{C}-\mathrm{C}$ coupling reactions catalysed not only by Pd but also other metals

\section{ACKNOWLEDGMENTS}

We highly acknowledge Mr Bilal Ahmad Bhat, Research fellow (Govt. Degree College) Shopian for providing necessary guidance and support.

\section{REFERENCES}

1. R.F., Heck; J.P., NolleyJr; "Palladium catalyzed vinylic hydrogen substitution reactions with aryl, benzyl, and styryl halides", 1972, 37, 2320.

2. P., Beletskaya; A.V., Cheprakov; "The Heck Reaction as a Sharpening Stone of Palladium Catalysis".Chem.Rev., 2000, 8, 3009.

3. M.,Ichiro; F., Yuzo, "Aromatic substitution of styrene-palladium chloride complex", Tetrahedron Letters, 1967, $8,1119$. 
4. G.A., Molander; C.R., Bernardi; "Suzuki-Miyaura Cross-Coupling Reactions of Potassium Alkenyltrifluoroborates”, J. Org. Chem., 2002, 67, 8424.

5. Brasc, S.; de Meijere, A. In Mertal Catalysed Cross Coupling Reactions; Ied.; Diederich, F., Stang, P.J., Eds.; Wiley-VCH: Weinhreim, 1998, 99.

6. Beletskaya, I. P.; Cheprakov, A. V. Chem. Rev. 2000, 100, 3009.

7. The Mizoroki-Heck Reaction; Oestreich, M., Ed.; Wiley: West Sussex, 2009

8. Dounay, A.B.; Overman, L. E. Chem. Rev. 2003, 103, 2945.

9. Shibasaki, M.; Vogl, E. M.; Ohshima, T. Adv. Synth.Catal. 2004, 346, 1533.

10. Beller, M.; Riermeier, T. H.; Stark, G. In Transition Metals for Organic Synthesis; I ed.;Beller, M., Bolm, C., Eds.; Wiley-VCH: Weinheim, 1998, 1, 208.

11. Vyvyan, J.R.; Peterson, Emily A.; Stephan, Mari L. “(+/-)-caparratriene”.Tetrahedron Letters.1999, 40, 27, 4947.

12. Negishi, E.-I., King, A.O., Okukado, N.: J. Org. Chem. 1977, 42, 1821

13. Phapale, V.B., Cardenas, D.J.: Chem. Soc. Rev., 2009, 38, 1598.

14. Kurti L, Czako B. Strategic Applications of Named Reactions in Organic Synthesis New York: Elsevier Academic Press, 2005.

15. Andrew G Myers Research Group. “Chemistry 115 Handouts” .Boston, Massachusetts: Harvard University Department of Chemistry.

16. Casado AL, Espinet P Organometallics. 1998, 17, 5, 954.

17. Crabtree R. The organometallic Chemistry of the Transition Metals. 4. Hoboken, NJ: John Wiley and sons Inc. 2005.

18. Negishi, E.-I.: Acc. Chem. Res. 1982, 15, 340 .

19. Tykwinski, R.R.: Angew. Chem. Int. Ed. 2003, 42, 1566 .

20. Chinchilla, R., Naijera, C.: Chem. Rev., 2007, 107, 874.

21. Chinchilla, R., Naijera, C.: Chem. Soc. Rev., 2011, 40, 5084.

22. Bunz, U.H.F.: Chem. Rev.2000, 100, 1605

23. Zapf, A., Beller, M.: Top. Catal., 2002, 19, 101.

24. Torborg, C., Beller, M.: Adv. Synth. Catal. 2009, 351, 3027.

25. Diek, H. A.; Heck, F.R.J. Orgamomet. Chem.1975, 93, 253

26. Cassar, L. J. Organomet. Chem. 1975, 93, 253

27. Sonogashira, K.; Tohda, Y.; Hagihara, N. Tetrahedron Lett. 1975, 16, 4467

28. Stephens, R.D.; Castro, C.E.J. Org. Chem. 1963, 28, 2163

29. Ljungdahl, T., Pettersson, K., Albinsson, B., Martensson, J.:J. Org. Chem. 71, 1677 (2006) 
30. Gelman, D., Buchwald, S.L.: Angew. Chem. Int. Ed. 42, 5993 (2003)

31. Fukuyama, T., Shinmen, M., Nishitani, S., Sato, M., Ryu, I.: Org. Lett. 4, 1691 (2002)

32. Soheili, A., Albaneze-Walker, J., Murry, J.A., Dormer, P.G., Hughes, D.L.: Org. Lett.5, 4191 (2003)

33. Naijera, C., Gil-Molto, J., Karlstrom, S., Falvello, L.R.: Org. Lett. 5, 1451 (2003)

34. Ruiz, J., Cutillas, N., Lopez, F., Lopez, G., Bautista, D.: Organometallics, 2006, $25,5768$. 